\title{
Impact of HPV Infection on the Quality of Life in Young Women
}

\author{
J. Escalas ${ }^{*}, 1$, C. Rodriguez-Cerdeira ${ }^{2}$ and A. Guerra-Tapia ${ }^{3}$ \\ ${ }^{I}$ Dermatology department, Hospital Son Dureta, Islas Baleares, Spain \\ ${ }^{2}$ Dermatology Department, CHUVI \& University of Vigo, Vigo, Spain \\ ${ }^{3}$ Dermatology Department, Hospital Doce de Octubre, Madrid, Spain
}

\begin{abstract}
The possibility to acquire sexually transmitted diseases generates bio-psycho-social conflicts affecting women's daily lives. We try to investigate the knowledge of women on the concept of being infected by the human papilloma virus (HPV) and to understand the significance they attributed to their condition as HPV carriers. Studies on women who have had anomalous Pap Test results have highlighted psychological consequences like anxiety, fear of cancer, sexual problems, changes in body image, difficulty in reproductive functions, hypochondria, a sense of heedlessness and anger.
\end{abstract}

We think that it is possible to understand the necessity of assistance, orientation and the opportunity to listen to them, offering individualized quality care.

Keywords: HPV, mental disturbs, quality life.

\section{INTRODUCTION}

The Human Papilloma Virus (HPV) is one of the most common causes of sexually transmitted diseases, some viral subtypes infect the genital mucosa, causing cellular abnormalities in Tap Tests and otherwise diagnosed by means of colcoscopy and biopsies [1]. There is a direct association of some types of HPV with cervical carcinoma. More than 120 genotypes that infect man have been identified, with specific types of HPV that infect the genital tracts of men and women numbering about 30. Types of HPV are subdivided into categories of low and high risk for ceroplastic transformation. The low and high risk genotypes are associated with benign lesions, like the anogenital condyloma or genital warts while some types of anogenital HPV $(16,18,31,33,35)$ are strongly associated with intraepithelial neoplasia of the cervix, of the vulva, of the penis, and anus and its progression to invasive carcinoma [2]. Cervical carcinoma was the first cancer to be recognised by the World Health Organisation as being totally ascribable to an infection.

HPV infections are very common in the population: it is estimated that more than $75 \%$ of sexually active women are infected with an HPV during their lifetime, peaking with women between the ages of 18 and 25 . Only $1 \%$ of the population will develop condylomatosis florida lesions, while the infection causes subclinical lesions in the majority of cases. The infection is often asymptomatic and in most cases $(70-90 \%)$ transitory, because the virus is eliminated by the immune system before developing a pathogenesis effect. The persistence of the viral infection is a necessary condition for the development of a carcinoma [3, 4].

*Address correspondence to this author at the Dermatology Department, Hospital Son Dureta, Palma de Mallorca, Spain; Tel: 670084531; Fax: 0034-971208616; E-mail: jetpalma@hotmail.com
Although it is clear that the human papillomavirus plays an important role in tumoral development, it is just as evident that the viral infection alone is not sufficient to cause a cervical tumour. The malign transformation of a normal epithelial cell also depends on other physical and chemical oncogenous factors like cigarette smoke, the long term use of oral contraceptives, co-infection of other sexually transmitted diseases a high number of sexual partners, a higher age, a high number of births. The risk of developing a tumour also depends on the balance between the immune system and the genetic characteristics of the host [5].

Studies on women who have had anomalous Pap Test results have highlighted psychological consequences like anxiety, fear of cancer, sexual problems, changes in body image, difficulty in reproductive functions, hypochondria, a sense of neglect, anger, and fear of being labelled [6-8].

There are hardly any papers published about the impact on the quality of life of the patients with HPV infection. We have chosen two of them which we consider the most relevant ones. These two studies assess the impact of the HPV infection on the quality of life in young women.

With the development of new vaccines a new way of hope has opened up $[9,10]$.

\section{FIRST STUDY}

As the only national non-governmental organisation (NGO) in the USA dedicated to the prevention and control of all sexually transmitted diseases (STDs), the American Social Health Association (ASHA) provides education and support to thousands of people with STDs and to their physicians and other health care providers [11].

To better understand the impact of HPV infection on patients' lives, in 1992 ASHA surveyed a sample of the people served by its HPV Support Program. 
A sample of 837 individuals was chosen from the mailing list for HPV news. Of the 837 people who were mailed the 11 page questionnaire, 489 returned surveys, a $58 \%$ response rate. Excluded from analysis were surveys that were received after the deadline, were incomplete, or were from respondents who did not have HPV (total excluded, $\mathrm{n}=35$ ). A total of 454 surveys were analysed.

The self-administered questionnaire contained nearly 80 questions addressing 4 major areas: medical history, healthcare experiences, personal impact, and general demographic information.

Respondents were asked to comment on the impact of HPV both at diagnosis and within the last 12 months, if applicable.

Respondents comprised 349 (77\%) women and 105 (23\%) men. Seventy-six per cent of the group was at least 30 years of age, with $37 \%$ between 30 and 39 years of age,

Nearly half $(49 \%)$ of the respondents reported that they had had HPV for 3 years or more. Only $15 \%$ reported having had HPV for less than one year. The majority $(60 \%)$ reported having had visible genital warts at some time; however, a larger proportion of men $(94 \%)$ said they had visible warts than women (49\%).

Men reported having HPV most frequently on the penis $(92 \%)$, anal area $(21 \%)$, and scrotum $(20 \%)$. Sixty per cent of the women reported having HPV on the cervix $50 \%$ on the labia or vulva, $45 \%$ in the vagina, and $20 \%$ in the anal area.

\section{EMOTIONAL IMPACT}

The majority of respondents noted a range of negative feelings when they first discovered they had HPV. Initial reactions included anger, depression, isolation, shame and guilt. For all descriptive emotional states, the percentage of people self-reporting the influence of HPV infection on these aspects of their lives decreased over time. Fewer people reported negative emotions due to HPV infection during the past year, however over one-third continued to experience some effect.

Many respondents $(73 \%)$ said they were concerned about transmitting HPV and many (57\%) were concerned about being judged negatively by an acquaintance since they felt their infection. Discovery of HPV infection also adversely affected sexual feelings. Seventy-two per cent of respondents felt less desirable due to their HPV infection, and $68 \%$ reported enjoying sexual contact less. During the past year, $47 \%$ said they continued to feel less desirable, and $42 \%$ enjoyed sexual contact less since they felt their infection would cause them to be rejected by a potential sexual partner. Nineteen per cent had in fact been rejected by a potential sexual partner because of their HV infection.

\section{IMPACT ON BEHAVIOUR}

The influence of HPV infection on sexual behaviour and sexual relationships was reported with high frequency. Eight-six per cent said that, following the initial diagnosis, their infection affects their ability to approach a new partner; $73 \%$ were spontaneous in their sexual activity; and $72 \%$ had sex less frequently. During the 12 months following the survey, however, these numbers fell. One half continued to feel less spontaneous in their sexual activity and $48 \%$ still noted less frequent sexual contact. The majority (71\%) also said their infection affected their ability to approach a new partner.

\section{CONCLUSION}

The results reported in this survey demonstrate that HPV infection can cause emotional upheaval and anxiety for many, adversely affecting self-image and creating a perception of being stigmatised and alienated. Two-thirds or more experienced depression, isolation, or shame, feared rejection, or felt less desirable when they discovered they were infected. One third or more continued to experience these findings in the 12 months after the survey.

\section{SECOND STUDY}

The objective was to evaluate the effect of communication and HPV diagnosis on the cognitivebehavioural aspect, emotional experiences, psychic-physical well-being, and psychosexual sphere in young women between the ages of 20 and 45 [12].

Method: during the period between February 2006 and March 2007, the U.O. Department of Obstetrics and Gynaecology of the ULSS 13 of Mirano (Verona), distributed three self evaluating questionnaires (The Cba-20, the SAT.P and the BISF-W) to 36 women had been diagnosed with an HPV infection and 36 women who had never been diagnosed with HPV.

The objectives of this study were to investigate whether or not the communication of being affected by human papilloma virus by a physician influences the quality of life and the psychophysical well-being of women between the ages of 20 and 45.

The questionnaire used in this study was the following:

CBA 2.0 (Cognitive Behavioural Assessment, by Bertolotti, Micheielin, Savanio, Simonetti, Vidotto, And Zotti, in 1986: set of 9 cards that measures the cognitivebehavioural aspects. In this study we considered:

Card 2 (STAI-X2): measures state of anxiety and consists of 20 items.

Card 3 (STAI-X2): measures trait anxiety and consists of 20 items

Card 4: Evaluates trait anxiety manifested by the subject at the conclusion of the battery and offers the possibility of comparison with the level of anxiety manifested at the beginning of the compilation of the questionnaire.

Card $6(\mathrm{QPF} / \mathrm{R})$ consisting of 30 items, this card investigates psych-psychological relations and disturbances of potential clinical significance

Card 7 (IP/R) allows the compilation of two overall indexes and five subscales that study specific groupings of fear

Cards 8 (IP/R) consisting of 21 items, this card measures dysphoria and depressive manifestations of subclinical significance

Card $9(\mathrm{MOCQ} / \mathrm{R})$ consisting of 21 items, this card supplies the overall score and the indexes, studies intrusive thoughts and compulsive behaviours. 


\section{CONCLUSIONS}

The study concludes that HPV diagnosis caused emotional reactions, especially fear and anxiety, in most subjects of our sample. The discovery of an infection affects levels of manifested anxiety, on intrusive and pervasive thoughts on obsessive and compulsive behavioural attitudes, and concerns regarding hygiene, infection, and contamination. The HPV diagnosis does not significantly influence the quality of the sexual sphere; however, it did come to light that most women affected by HPV indicated health problems when asked which factor most influenced their sexual activity.

The mental representation of the infection and the potential implications, together with the emotions involved like anxiety and fear of cancer to the obsession towards hygiene and infection, may converge in attitudes that are expressed in obsessively and compulsively protective behaviours towards personal health care.

\section{REFERENCES}

[1] Bologna JL, Jorizzo JL, Rapini RP. Dermatología $1^{a}$ edición español. Madrid: Elsevier España, SA, 2004.

[2] Pagliusi S, Garland S. International standards reagents for HPV detection. Dis Markers 2007; 23: 283-96.
[3] Klencke B, Palefsky J. Anal cancer: and HIV-associated cancer. Hematol Oncol Clin North 2003; 17: 859-72.

[4] Rodríguez-Cerdeira C, Menéndez A, Bravo G, Alcántara R. El virus del papiloma humano y su repercusión en la patología genital femenina. Piel 2007; 22: 1171-80.

[5] Rodríguez-Cerdeira C, de Argila D, Guerra A. Tumores malignos. In: Guerra Tapia A, Ed.. Manual y atlas de enfermedades de la vulva. Barcelona: Glosa 2006; pp. 261-283.

[6] Lerman C, Miller SM, Scarborough R, et al. Adverse consequences of positive cytologic cervical screening. Am J Obstet Gynecol 1991; 165: 658-62.

[7] Rodríguez-Cerdeira C, Chillón R, Díez-Moreno S, Guerra-Tapia A Prevalence and genotypic identification of human papillomavirus infection in a population from northwestern spain. Open Dermatol J 2009; 3: 18-21.

[8] Khan JA, Slap G, Bernstein DI. Psychological, behavioural, and interpersonal impact of human papillomavirus and Pap test results. J Womens Health 2005; 14: 650-9.

[9] Rodríguez-Cerdeira C, Alba A, Vilata JJ. Desarrollo de nuevas vacunas contra el virus del papiloma humano. Piel 2007: 22(2). 513.

[10] Bergeron C, Largeron N, McAllister R, Mathevet P, Remy V. Cost effectiveness analysis of the introduction of a quadrivalent human papillomavirus vaccine in France. Int J Technol Assess Health Care 2008; 24: 10-19.

[11] Clarke P, Ebel C, Catotti DN, Stewart S. The psychosocial impact of human papillomavirus infection: implications for health care providers. Int J STD AIDS 1996; 7: 197 -200.

[12] Maggino T, Casadei D, Panontin E, et al. Impact $f$ an HPV diagnosis on the quality of live in young women Gynecologic Oncology 2007; 107: S 175-79. 